\title{
Changes in severity of 2009 pandemic A/H1N1 influenza in England: a Bayesian evidence synthesis
}

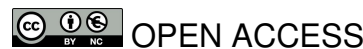

\author{
A M Presanis investigator statistician ${ }^{1}, \mathrm{R}$ G Pebody consultant epidemiologist ${ }^{2}$, B J Paterson \\ research fellow in epidemiology ${ }^{23}$, B D M Tom investigator scientist ${ }^{1}$, P J Birrell career development \\ fellow in biostatistics ${ }^{1}$, A Charlett Head of statistics, modelling and economics department ${ }^{2}, \mathrm{M}$ \\ Lipsitch professor of epidemiology ${ }^{4}$, D De Angelis senior statistician ${ }^{12}$
}

\begin{abstract}
${ }^{1}$ Medical Research Council Biostatistics Unit, Institute of Public Health, University Forvie Site, Cambridge CB2 0SR, UK; ${ }^{2} \mathrm{Health}$ Protection Agency Health Protection Services, London NW9 5EQ, UK; ${ }^{3}$ Hunter Medical Research Institute, University of Newcastle, Newcastle, Australia; ${ }^{4}$ Centre for Communicable Disease Dynamics, Departments of Epidemiology and Immunology and Infectious Diseases, Harvard School of Public Health, 677 Huntington Avenue, Boston, MA 02115, USA
\end{abstract}

\begin{abstract}
Objective To assess the impact of the $2009 \mathrm{~A} / \mathrm{H} 1 \mathrm{~N} 1$ influenza pandemic in England during the two waves of activity up to end of February 2010 by estimating the probabilities of cases leading to severe events and the proportion of the population infected.

Design A Bayesian evidence synthesis of all available relevant surveillance data in England to estimate severity of the pandemic.

Data sources All available surveillance systems relevant to the pandemic 2009 A/H1N1 influenza outbreak in England from June 2009 to February 2010. Pre-existing influenza surveillance systems, including estimated numbers of symptomatic cases based on consultations to the health service for influenza-like illness and cross sectional population serological surveys, as well as systems set up in response to the pandemic, including follow-up of laboratory confirmed cases up to end of June 2009 (FF100 and Fluzone databases), retrospective and prospective follow-up of confirmed hospitalised cases, and reported deaths associated with pandemic 2009 A/H1N1 influenza.
\end{abstract}

Main outcome measures Age specific and wave specific probabilities of infection and symptomatic infection resulting in hospitalisation, intensive care admission, and death, as well as infection attack rates (both symptomatic and total). The probabilities of intensive care admission and death given hospitalisation over time are also estimated to evaluate potential changes in severity across waves.

Results In the summer wave of $\mathrm{A} / \mathrm{H} 1 \mathrm{~N} 1$ influenza, $0.54 \%$ ( $95 \%$ credible interval $0.33 \%$ to $0.82 \%$ ) of the estimated 606100 (419 300 to 886300 ) symptomatic cases were hospitalised, $0.05 \%(0.03 \%$ to $0.08 \%)$ entered intensive care, and $0.015 \%(0.010 \%$ to $0.022 \%)$ died. These correspond to 3200 (2300 to 4700) hospital admissions, 310 (200 to 480) intensive care admissions, and 90 (80 to 110) deaths in the summer wave. In the second wave, $0.55 \%$ ( $0.28 \%$ to $0.89 \%$ ) of the 1352000 (829 900 to 2 $806000)$ estimated symptomatic cases were hospitalised, $0.10 \%(0.05 \%$ to $0.16 \%)$ were admitted to intensive care, and $0.025 \%(0.013 \%$ to $0.040 \%$ ) died. These correspond to 7500 (5900 to 9700 ) hospitalisations, 1340 (1030 to 1790) admissions to intensive care, and 240 (310 to 380) deaths. Just over a third (35\% (26\% to $45 \%)$ ) of infections were estimated to be symptomatic. The estimated probabilities of infections resulting in severe events were therefore $0.19 \%(0.12 \%$ to $0.29 \%), 0.02 \%(0.01 \%$ to $0.03 \%)$, and $0.005 \%(0.004 \%$ to $0.008 \%)$ in the summer wave for hospitalisation, intensive care admission, and death respectively. The corresponding second wave probabilities are $0.19 \%(0.10 \%$ to $0.32 \%)$, $0.03 \%(0.02 \%$ to $0.06 \%)$, and $0.009 \%$ ( $0.004 \%$ to $0.014 \%)$. An estimated $30 \%(20 \%$ to $43 \%)$ of hospitalisations were detected in surveillance systems in the summer, compared with $20 \%$ (15\% to $25 \%$ ) in the second wave. Across the two waves, a mid-estimate of $11.2 \%(7.4 \%$ to $18.9 \%)$ of the population of England were infected, rising to $29.5 \%$ (16.9\% to $64.1 \%$ ) in 5-14 year olds. Sensitivity analyses to the evidence included suggest this infection attack rate could be as low as $5.9 \%(4.2 \%$ to $8.7 \%)$ or as high as $28.4 \%$ (26.0\% to $30.8 \%$ ). In terms of the probability that an infection leads to death in the second wave, these correspond, respectively, to a high estimate of $0.017 \%(0.011 \%$ to $0.024 \%)$ and a low estimate of $0.0027 \%(0.0024 \%$ to $0.0031 \%)$.

Conclusions This study suggests a mild pandemic, characterised by case and infection severity ratios increasing between waves. Results suggest low ascertainment rates, highlighting the importance of systems enabling early robust estimation of severity, to inform optimal public health responses, particularly in light of the apparent resurgence of the $2009 \mathrm{~A} / \mathrm{H} 1 \mathrm{~N} 1$ strain in the 2010-11 influenza season.

\section{Introduction}

Since the first confirmed cases of pandemic influenza A/H1N1 were reported in April 2009, 18449 deaths have been notified worldwide. ${ }^{1}$ Reported numbers of laboratory confirmed cases and deaths are of limited value in determining the severity of a 
disease because of the difficulties in identifying, testing, confirming, and reporting cases, particularly during a pandemic. ${ }^{2-8}$ For policy makers, however, understanding severity is crucial to determine appropriate public health responses. Severity estimates are needed early on in an outbreak, when timely (but perhaps not the most robust) estimates are required, but also when an epidemic has run its course, to quantify robustly both the severity and total burden of disease and to assess whether public health responses and surveillance systems were adequate in the midst of the epidemic. An assessment of severity is a key element in understanding the epidemiology of the 2009 pandemic and for planning for future pandemics, particularly if more severe or more transmissible influenza strains emerge. Furthermore, if unusual patterns of age specific mortality continue for several years, as has happened in past pandemics $^{9}$ and as seems to be the case with the 2009 pandemic, ${ }^{10}$ knowledge of the severity and burden of the strain is important for planning healthcare resource allocation as well as for understanding if severity is changing over time.

A measure of the severity of an infection is its case severity, the probability that an infected individual develops severe disease. Specifically, the case fatality ratio (the probability that an infection leads to death, estimated by taking the ratio of deaths to cases) is often used, together with the case hospitalisation ratio and case intensive care admission ratio (table $1 \Downarrow$ ). A case may be defined either as any infection or a symptomatic infection, meaning a febrile influenza-like illness. Although influenza typically causes symptomatic infection, a substantial proportion of infected individuals will be asymptomatic or have only mild symptoms. These individuals are unlikely to be identified unless serological testing is undertaken on a population basis. ${ }^{11}{ }^{12}$ Estimation is therefore required to obtain a quantification of severity. In this paper, we estimate the symptomatic case fatality, case intensive care admission, and case hospitalisation ratios (the probabilities of symptomatic infections leading to severe events (table $1 \Downarrow$ )) for pandemic A/H1N1 in England, from multiple sources of data available from various surveillance systems, and derive the corresponding infection severity ratios (the probabilities of all infections leading to severe events) using data from population sero-incidence surveys on the infection attack rate. ${ }^{13}$

Severity estimation is potentially complicated by two key problems affecting the observed numbers of severe events and cases - censoring and ascertainment bias. ${ }^{2-4-8}$ Censoring happens in the midst of an epidemic, when some severe events resulting from infections to date have yet to occur, leading to underestimation of the number of severe events. Ascertainment bias refers more generally to undercounting of cases because of surveillance systems not capturing all cases for multiple reasons. To estimate case severity ratios correctly, methods accounting for these biases are required. Previous attempts to estimate the symptomatic case fatality ratio of pandemic A/H1N1 in England ${ }^{3-15}$ have accounted for censoring but not all ascertainment biases and, in particular, have not accounted for all the uncertainty inherent in the data. Crucially, they have not used all the available information in the estimation process. To address these limitations, we adapted a Bayesian approach to severity estimation, ${ }^{8}$ synthesising all available relevant data and prior information on biases to derive estimates of the infection and case severity ratios, the infection attack rate, and the symptomatic attack rate in England. For a retrospective analysis, as presented here, censoring is no longer an issue, so we did not need to account for it, but our analytical approach is easily adapted to a mid-pandemic situation where censoring does induce bias. ${ }^{8}$ In accounting for ascertainment bias, we assessed the proportion of infections detected in both pre-existing surveillance systems monitoring seasonal influenza and systems specifically set up in response to the pandemic $\mathrm{A} / \mathrm{H} 1 \mathrm{~N} 1$ outbreak.

As England experienced two waves of pandemic A/H1N1 infection in 2009-10, we investigated changes in severity across the waves, comparing the periods 1 June to 31 August 2009 (summer) and 1 September 2009 to 28 February 2010 (autumn-winter). In absolute terms, more deaths and hospitalisations were observed from September to November than in the three summer months: it is important to understand whether this reflects greater numbers of infections in the autumn, better ascertainment, or a real increase in severity. The answer has important implications for surveillance and public health responses in future pandemics.

\section{Methods}

\section{Sources of information}

Several influenza surveillance systems at the Health Protection Agency provide data on pandemic A/H1N1 cases.

Confirmed cases-The FF100 ${ }^{16}$ and FluZone ${ }^{17}$ databases comprise detailed information on each of the first few thousand confirmed cases of pandemic A/H1N1 influenza, including dates of severe outcomes. From these, we estimated the delay from symptom onset to hospitalisation using a parametric mixture survival model,$^{18}$ giving an estimate (assumed unbiased) of the proportion of confirmed cases hospitalised, which we used indirectly in our Bayesian analysis. Since the survival model was fitted to data from early on in the epidemic, on confirmed cases that were followed up only until the end of June 2009, this is the only analysis where we have accounted for censoring.

Symptomatic cases-During the pandemic, the Health Protection Agency fitted a regression model to data on the number of consultations for influenza-like illness (in primary care and through the National Pandemic Flu Service) and to data on the positivity rate, to produce weekly age specific and region specific estimates ${ }^{19} 20$ of the number of symptomatic cases accessing healthcare. These were divided by estimates of the proportion of influenza-like illness cases in patients who consulted healthcare services, to obtain estimates of the total number of symptomatic cases. These are thought to underestimate the true symptomatic attack rate, given other evidence on the infection attack rate. ${ }^{13}$

Seroincidence-Repeated cross sectional serological surveys were undertaken as part of the annual collection of residual sera for the Health Protection Agency sero-epidemiology programme from patients accessing healthcare in England. Data from these surveys, taken before the pandemic (a 2008 baseline), after the first wave of infections in August-September 2009, ${ }^{13}$ and after the second wave $^{21}$ are published, providing evidence (though highly uncertain because of small sample sizes, low power, and potential biases in the sampled population) on the age specific infection attack rate during both waves.

Hospitalisation-A web based surveillance system in England was established by the Health Protection Agency and

Department of Health after the end of the first wave in August $2009^{22}$ to ascertain and collect data on all confirmed cases of pandemic $\mathrm{A} / \mathrm{H} 1 \mathrm{~N} 1$ influenza hospitalised in acute NHS trusts in England. Of these, 970 cases, confirmed during the first wave, were retrospectively added to the database and 1306 cases were added prospectively during the second wave. Ascertainment of cases, however, was incomplete, with only $129(77 \%)$ of the 168 acute NHS hospital trusts in England participating. This 
database provided information (from a line listing at 9 July 2010) on the number of hospitalisations of confirmed cases and on the ratios of intensive care admissions and deaths to hospitalisations. We considered the observed hospitalisations to reflect only a subset of all pandemic $\mathrm{A} / \mathrm{H} 1 \mathrm{~N} 1$ hospitalisations but assumed the observed ratios of intensive care admission to hospitalisation and death to hospitalisation provided unbiased information on the probabilities of severe events given hospitalisation. $^{18}$

Death-As at 9 July 2010, 380 deaths among people with confirmed pandemic $\mathrm{A} / \mathrm{H} 1 \mathrm{~N} 1$ infection or mention of influenza on the death certificate had been reported to the Health Protection Agency or the chief medical officer. ${ }^{14}{ }^{15}$ Among individuals with symptom onset from 1 June to 31 August, 79 deaths were observed in the summer wave, and 301 deaths were observed in the second wave among individuals with symptom onset 1 September to 28 February. A capture-recapture analysis suggests that deaths were under-ascertained by approximately $10 \% .{ }^{23}$

\section{Estimation approach}

We adapted a Bayesian approach to estimate the attack rates, infection severity ratio, and symptomatic case severity ratio. ${ }^{8}$ We considered five severity levels (infection, symptomatic infection, hospitalisation, intensive care admission, and death (fig $1 \Downarrow)$ ), denoted $\mathrm{g}=I N F, S, H, I$, and $D$; and seven age groups, $<1,1-4,5-14,15-24,25-44,45-64$, and $\geq 65$ years.

We defined $N_{a, t, g}$ to be the number of infections in age group $a$, wave $t$, and severity level $g$ (table $2 \Downarrow$ ), and defined $c_{a, t, g k}$ to be the probability that pandemic $\mathrm{A} / \mathrm{H} 1 \mathrm{~N} 1$ cases in age group $a$ and wave $t$ at severity level $k$ progress to level $g$ (namely, the ratio of cases at level $g$ to those at level $k$ if cases at $g$ are a subset of those at $k$ (such as if all deaths occur in hospital)). Then the infection and symptomatic case severity ratios were expressed as products of the component probabilities of progressing through each successive level of the severity pyramid (fig $1 \Downarrow$, table $2 \Downarrow$ ). For example, the case fatality ratio was defined as the product of the probability of hospitalised cases dying, the probability of symptomatic cases being hospitalised, and the probability of an infection being symptomatic:

$c_{a, t, D V N F}=c_{a, t, D \backslash H} c_{a, t, H S} c_{a, t, S V N F}$. These components were estimated by synthesising the available information on infection at each severity level and on ascertainment probabilities, $d_{a, t, g}$, the probabilities that severe events were captured by surveillance systems (table $2 \Downarrow$ ). Further combining with population sizes, we also obtained estimates of the infection and symptomatic attack rates.

To do this, we combined the observed surveillance data with our knowledge of each probability before observation, summarised by a "prior" distribution, to obtain an updated distribution (the "posterior") which formally summarised our final knowledge of the quantities of interest. This distribution, accounting for both imperfect detection and all uncertainty inherent in the data as well as uncertainty about some model assumptions through the introduction of informative prior distributions,${ }^{18}$ was summarised by its centiles - the median and the 2.5 and 97.5 centiles (denoted the $95 \%$ credible interval). The Bayesian analysis was carried out in OpenBUGS. ${ }^{24}$

\section{Statistical model}

Figure $2 \Downarrow$ illustrates the relation between the data and the quantities to be estimated. Full model details are given by Presanis et $a l^{18}$ but are briefly described here, with table $2 \Downarrow$ summarising the model parameters. The Bayesian evidence synthesis combined both direct (solid lines, fig $2 \Downarrow$ ) and indirect information on each parameter, where indirect evidence might take the form of data on other quantities indirectly influencing the parameter of interest (such as the number of deaths informing the number of hospitalisations) or model assumptions.

Data from the sero-incidence study ${ }^{13}$ were used to inform the infection attack rate in the summer wave $\left(c_{a, \text { Summer,INFPOP }}\right)$. We considered the Health Protection Agency estimates of symptomatic infection ${ }^{19}{ }^{20}$ to be biased downwards, providing information on a quantity $\left(N_{a, t S B}\right)$ that was a proportion of the true number of symptomatic cases $\left(N_{a, t, s}\right.$, where $d_{a, t, S}$ denotes this proportion). This proportion was estimated in the first wave of influenza from the information on the infection attack rate in combination with prior information on the proportion $\left(c_{S V N F}\right)$ of infections that are symptomatic (table $1 \Downarrow$ ). This proportion symptomatic was assumed to be equal across age groups ${ }^{25}$ and waves. By assuming the age specific bias in the Health Protection Agency estimates, $d_{a, t, S}$, was similar, but not necessarily equal, in the two waves (table $1 \Downarrow$ ), we estimated the number of symptomatic infections $N_{a, s}$ in the autumn-winter period. ${ }^{18}$ Combined again with the prior information on the proportion of infections which are symptomatic, we obtained an estimate of $N_{a, t, I N F}$ in the autumn-winter wave.

The detected number of hospitalised cases ${ }^{22}$ and deaths ${ }^{14}{ }^{15}$ were considered a subset of the true number of cases, $N_{\text {a.t. }}$, for $g=H, D$ respectively, with corresponding detection probability, $d_{t, g}$, assumed equal across age groups. Similarly, the observed number of intensive care admissions and deaths from the subset of hospitalisations with non-missing data on outcomes were a proportion of the observed number in the subset, denoted $c_{a, t, g \mathrm{H} H}$ for $g=I, D$, respectively (table $2 \Downarrow$ ).

Each age specific symptomatic case hospitalisation ratio, $c_{a, t, H S}$, was constrained to be less than the corresponding age specific confirmed case hospitalisation ratio. These confirmed case hospitalisation ratios were themselves informed by the age specific estimates given by a parametric mixture survival model..$^{18}$ After accounting for censoring, the estimated confirmed case hospitalisation ratio averaged over age was $1.20 \%(95 \%$ confidence interval $0.97 \%$ to $1.49 \%$ ).

Importantly, we assumed the detection probabilities to be less than $100 \%$ for both hospitalisations and deaths. We gave $d_{t, H}$ a vague prior distribution (table $2 \Downarrow$ ) that accounts for under-ascertainment. We chose a prior distribution for $d_{t, D}$ with mean $90 \%$, ranging between $80 \%$ and $97 \%$, based on a capture-recapture study, ${ }^{23}$ to reflect under-ascertainment due to test sensitivity or other reasons for failing to appear in surveillance systems. We allowed both $d_{t, H}$ and $d_{t, D}$ to vary by wave, but not age.

\section{Results}

Table $3 \Downarrow$ shows that in the summer wave of influenza, $0.54 \%$ ( $95 \%$ credible interval $0.33 \%$ to $0.82 \%$ ) of the estimated 606 100 (419300 to 886300 ) symptomatic cases were hospitalised, corresponding to 540 (330 to 820) out of every 100000 symptomatic cases and to a total of 3200 (2300 to 4700) hospitalisations. Of the symptomatic cases in this first wave, $0.05 \%(0.03 \%$ to $0.08 \%)$ entered intensive care (corresponding to 310 (200 to 480) intensive care admissions) and $0.015 \%$ ( $0.010 \%$ to $0.022 \%)$ died (90 (80 to 110$)$ deaths).

In the second wave, $0.55 \%$ ( $0.28 \%$ to $0.89 \%)$ of the 1352000 (829 900 to 2806000 ) estimated symptomatic cases were hospitalised, corresponding to 7500 (5900 to 9700) admissions. Of the symptomatic cases in the second wave, $0.10 \%(0.05 \%$ to $0.16 \%$ ) entered intensive care (1340 (1030 to 1790) 
admissions) and $0.025 \%$ (0.013\% to $0.040 \%)$ died (340 (310 to 380 ) deaths).

Just over a third ( $35 \%$ ( $26 \%$ to $45 \%)$ ) of infections were estimated to be symptomatic. The estimated probabilities of infections resulting in severe events were therefore $0.19 \%$ ( $0.12 \%$ to $0.29 \%), 0.02 \%$ ( $0.01 \%$ to $0.03 \%$ ), and $0.005 \%$ $(0.004 \%$ to $0.008 \%)$ in the summer wave for hospitalisation, intensive care, and death, respectively. The corresponding second wave proportions were $0.19 \%(0.10 \%$ to $0.32 \%), 0.03 \%$ ( $0.02 \%$ to $0.06 \%)$, and $0.009 \%$ ( $0.004 \%$ to $0.014 \%$ ) (table $3 \Downarrow)$. Age specific infection and case severity ratios are given in figure $3 \Downarrow$. The case fatality ratios, for both symptomatic cases and all cases, differed substantially across waves (table $3 \Downarrow$ ), with $93.5 \%$ posterior probability that these were greater in the autumn-winter wave than in the summer. The age specific differences over time were less pronounced (fig $3 \Downarrow$ ). The probabilities of intensive care admission and death among hospitalised patients also increase over time (fig $4 \Downarrow$ ). We estimated a cumulative infection attack rate across the two waves of $11.2 \%(7.4 \%$ to $18.9 \%$ ), with age specific and wave specific estimates given in table $4 \Downarrow$.

The observed number of hospitalisations in the autumn-winter wave was 1481 , representing an estimated $20 \%$ (15\% to $25 \%$ ) of the estimated 7500 (5900 to 9700) hospitalised cases (table $3 \Downarrow$ ), a substantial bias. Surveillance of suspected (rather than confirmed) cases of pandemic $\mathrm{A} / \mathrm{H} 1 \mathrm{~N} 1$ influenza indicated that 17519 of these were hospitalised in the autumn-winter wave ${ }^{17}$ : comparison with our estimate of the number of hospitalised cases (table $3 \Downarrow$ ) therefore suggests between $34 \%$ and $55 \%$ of suspected cases were true cases. An estimated 30\% (20\% to $43 \%$ ) of hospitalisations were detected in surveillance systems in the summer, compared with $20 \%$ (15\% to $25 \%$ ) in the second wave. The bias in the Health Protection Agency case estimates, averaged across age, was substantial but uncertain, with the case estimates $N_{a, t S B}$ representing $40 \%$ (24\% to $59 \%$ ) of the true number of symptomatic cases, $N_{a, t, S}$, in the summer and $36 \%$ ( $19 \%$ to $57 \%$ ) of them in the autumn-winter.

\section{Sensitivity analyses}

Several sensitivity analyses to the choice of denominator data and to the prior distribution of the infection attack rate were performed to further assess the uncertainty in the attack rates. ${ }^{18}$ Differences due to the choice of prior distribution of the infection attack rate were small relative to the differences due to choice of denominator data, so we concentrated on sensitivity to the denominator. Specifically, four models with different denominators were considered: (1) Health Protection Agency case estimates only, assumed unbiased; (2) the model presented in the main results section, with both the case estimates (assumed biased downwards) and the summer sero-incidence data, and the second wave attack rates obtained by assuming a similar bias in the Health Protection Agency case estimates in the two waves; (3) using the sero-incidence data from both waves, ${ }^{1321}$ assuming these are unbiased and that the Health Protection Agency case estimates are biased downwards; and (4) using the sero-incidence data from both waves, ${ }^{1321}$ assuming these are biased upwards and the Health Protection Agency case estimates are biased downwards.

The estimates of the infection attack rate in both waves across the four different choices of denominator may be as low as 5.9\% ( $4.2 \%$ to $8.7 \%$ ) (model 1 ) or as high as $28.4 \%$ (26.0\% to $30.8 \%$ ) (model 3), with the corresponding estimates for 5-14 year olds varying between $17.9 \%$ (11.5\% to $28.4 \%$ ) and $58.8 \%(52.8 \%$ to $64.5 \%$ ). The estimates of the case fatality ratio in the second wave were therefore highest in model 1 at $0.017 \%(0.011 \%$ to $0.024 \%)$ and lowest in model 3 at $0.0027 \%(0.0024 \%$ to $0.0031 \%)$.

\section{Discussion}

This study suggests a mild pandemic, with case and infection severity ratios highest in children and older adults and increasing over time. Infection attack rates were highest among school age children. The results suggest under-ascertainment of severe cases through routine systems and considerable uncertainty in the denominators of symptomatic and all infection, highlighting the limits of current surveillance. Robust systems are essential for future early estimation of severity.

\section{Variation by age and wave of influenza}

The case severity ratio estimates show a clear $U$ shape to the age distribution (fig $3 \Downarrow$ ), in contrast to the estimated infection and symptomatic attack rates (table $4 \Downarrow$ ), which have an inverted $\mathrm{U}$ shape, with the peak in school age children. These distributions indicate that proportionately fewer adults were infected than children, with 5-14 year olds having an infection attack rate of $29.5 \%$ (16.9\% to $64.1 \%$ ), whereas young and old cases were most likely to be severely affected. Among those hospitalised, the age distribution was again different, with the probability of severe outcomes increasing with age (fig $4 \Downarrow$ ), possibly due to increased risk of comorbidities. ${ }^{22}$ Although children and older adults were more likely than other adults to be admitted to hospital, once there, children were less likely than adults to enter intensive care or to die.

Our estimates of the number of hospitalisations and corresponding detection probability suggest a large bias in the observed hospitalisations due to under-ascertainment of confirmed cases. However, the estimated number was still substantially smaller than the observed suspected number of hospitalisations, suggesting between $34 \%$ and $55 \%$ of suspected hospitalisations in the autumn-winter wave were true pandemic A/H1N1 influenza cases. We estimated an increase in infection, case, and hospitalisation severity ratios between waves. The age specific increases were slightly less evident than the overall increases, because of the smaller sample sizes and hence greater uncertainty.

The higher severity among hospitalised cases older than 25 years estimated in the second wave (fig $4 \Downarrow$ ) may indicate a change in healthcare seeking behaviour or hospital admission policy, or may represent a real increase in severity. Initially, when less was known about risk groups and outcomes, individuals may have been more likely to seek healthcare and hospitals more cautious in admitting suspected cases than during the second wave, ${ }^{26}{ }^{27}$ so that those observed in hospital in the second wave may have had more severe illness on average than those hospitalised in the first wave. The difference between waves was less pronounced in children and young adults, possibly because the same cautious hospital admission behaviour may have applied to this population throughout.

\section{Uncertainties and assumptions}

Although behaviour change might explain the increase in probabilities of severe outcomes after hospitalisation, it might not be the only contributory factor to the increase in symptomatic case severity ratios. It is possible that a true increase in severity may have played a part in the estimated increase if, for example, other effect modifying factors such as 
bacterial super-infection were more common in the autumn-winter wave than in the summer, as was observed. ${ }^{28} 29$ If behaviour change had played a large part in the estimated increase in severity, then we might not have accounted adequately for under-ascertainment in the denominator of symptomatic cases, despite finding a substantial though uncertain bias in the Health Protection Agency estimates, or we may have overestimated the case hospitalisation ratio in the second wave. Alternatively, the observed ratios of intensive care admission to hospitalisation and death to hospitalisation ratios (assumed to provide unbiased information) may actually have been biased.

Other unaccounted factors might also have influenced apparent changes in severity, such as any potential shift in the age distribution of incident cases,${ }^{30}$ the use of antiviral drugs as prophylaxis or treatment, and the vaccination campaign. These last two factors might be postulated to reduce rather than increase severity. ${ }^{17}$ However, vaccination uptake increased only towards the second half of the second wave, ${ }^{17}$ so it might not have had a large effect on severity. Also, the per population rate of collection of antivirals via the National Pandemic Flu Service was lower in the second wave than in the first,${ }^{17}$ so if the attack rate was larger in the second than in the first wave, the effect of antivirals on reducing severity might have been greater in the first wave than in the second.

The estimated infection attack rate across all ages in the summer wave of $3.4 \%$ (2.4\% to $4.8 \%$ ), and the corresponding rate in $5-14$ year olds of $10.0 \%$ (5.9\% to $14.9 \%$ ), are somewhat smaller than those estimated from the sero-incidence data alone in London and the West Midlands, but larger than those estimated from the sero-incidence data alone in other regions. ${ }^{13}$ Thus there may have been regional difference ${ }^{13}$ that were smoothed over by our estimates averaged across England. A regional analysis may be beneficial, although the consequent small sample sizes would entail large uncertainty in such estimates.

The differences also highlight the uncertainties surrounding the estimation of attack rates, as evidenced by the relatively wide credible intervals, particularly for the age specific rates (table $4 \Downarrow$ ). Results from our sensitivity analyses show that the attack rate estimates are highly dependent on the model and data used, further emphasising the uncertainties surrounding the

denominators. The sensitivity of results to data used to inform denominators ${ }^{18}$ suggests further work is needed in synthesising all available data. It is clear that the evidence on denominators provided by the sero-incidence data and by the Health Protection Agency estimates conflict, the extent to which either source may be biased is less apparent.

The Health Protection Agency case estimates relied on broad assumptions about the proportion of individuals with influenza-like illness who contacted healthcare services, ${ }^{20}$ without allowing for a likely substantial change in this proportion over the course of the epidemic. ${ }^{31}$ Further, the Health Protection Agency case estimates represent numbers symptomatic where symptomatic is interpreted as presentation with febrile influenza-like illness due to pandemic $\mathrm{A} / \mathrm{H} 1 \mathrm{~N} 1$, and may therefore miss individuals with milder symptoms due to pandemic $\mathrm{A} / \mathrm{H} 1 \mathrm{~N} 1{ }^{20}$

On the other hand, as Miller and colleagues ${ }^{13}$ and Hardelid et $\mathrm{al}^{21}$ point out, their cumulative incidence estimates rely on the definition of "positivity" used, as well as on an assumption that the study population is representative of the population of interest. There is concern that the serology samples taken during the pandemic might have come from a population at greater risk of infection than average, and therefore more likely to have been vaccinated in the second wave, possibly introducing bias. ${ }^{132132}$ The authors also point out that small sample sizes imply limited power to detect changes in prevalence, particularly in older age groups. Care should therefore be taken not to over-interpret the estimates from our sensitivity analyses.

The model on which our main results are based (model 2 in our sensitivity analyses) incorporates uncertainty in the estimates that approximately covers the range, by age group, of the uncertainty in the estimates from model 1 and model 3, the two models which assume unbiased Health Protection Agency case estimates and unbiased sero-incidence data, respectively. Our estimates of the proportion of cases that were symptomatic (ranging from $30 \%$ (21\% to $40 \%$ ) to $39 \%$ (30\% to $49 \%$ ) in the sensitivity analyses) are broadly comparable with estimates from studies of seasonal influenza ${ }^{11}{ }^{12}$ and other studies of pandemic $\mathrm{A} / \mathrm{H} 1 \mathrm{~N} 1 .^{25}{ }^{33-35} \mathrm{~A}$ further sensitivity analysis ${ }^{18}$ to the choice of prior information on the proportion of infections that are symptomatic (mean prior value 63\% (95\% credible interval $50 \%$ to $76 \%)^{12}$ ) gives a posterior estimate of $55 \%$ (40\% to $69 \%$ ), with estimates of symptomatic case severity and the infection attack rate mildly sensitive to this choice. However, the difference in estimates is outweighed by the uncertainties in the denominators of symptomatic infection and all infection.

Our estimates rely on some assumptions of representativeness, such as that observations from hospital surveillance are representative of all English hospitals, not just those participating in the scheme, and that reporting practices did not change between the two waves of influenza. Finally, by using the sero-incidence data to infer the infection attack rate, we are implicitly assuming that by "infection" we mean infection with detectable antibody response, since we did not adjust for test sensitivity. Given the small sample sizes, concerns about the representativeness of the serology data, and the uncertainty in the denominators, we believe any uncertainty due to test sensitivity will be relatively small.

\section{Comparison with other studies}

Our analysis gives definitive estimates of the case severity ratios in England, lying between the US estimates based on medical attendances in Milwaukee and hospitalisations in New York (approach 1 in paper by Presanis et $\mathrm{al}^{8}$; symptomatic case fatality ratio $0.048 \%(0.026 \%$ to $0.096 \%)$ ) and the estimates based on self reported influenza-like illness in New York (approach 2 in paper by Presanis et $\mathrm{al}^{8}$; symptomatic case fatality ratio $0.007 \%$ $(0.005 \%$ to $0.009 \%)$ ). Our estimates are somewhat lower than the early estimates of the confirmed case fatality ratio provided by Garske et al, ${ }^{3}$ which ranged from $0.11 \%$ to $1.47 \%$ overall and from $0.13 \%$ to $0.41 \%$ in the UK, accounting for censoring. These were based, however, only on confirmed cases as a denominator, so were expected to be larger. Nishiura et $\mathrm{al}^{4}$ likewise considered confirmed cases as a denominator, accounting for censoring, and estimating between $0.16 \%$ and $4.48 \%$ of these in the US and Canada to be fatal.

Our estimates are more comparable with other estimates where infections or symptomatic infections were used as a denominator: Wilson and Baker ${ }^{6}$ estimated a range for the case fatality ratio of $0.0004 \%$ to $0.06 \%$, and Baker et $\mathrm{al}^{7}$ estimated a symptomatic case fatality ratio of $0.005 \%$, somewhat lower than ours. Hadler et $\mathrm{al}^{36}$ estimated a range for the symptomatic case fatality ratio in New York between $0.0054 \%$ and $0.0086 \%$, whereas Donaldson et $\mathrm{al}^{14}$ reported a symptomatic case fatality ratio for England of $0.026 \%$ (range $0.011 \%$ to $0.066 \%$ ), and Pebody et $\mathrm{a}^{15}$ reported a ratio of $0.04 \%$ (range $0.02 \%$ to $0.10 \%$ ). 
Wu et $\mathrm{al}^{37}$ estimated a case fatality ratio of $0.0109 \%(0.0041 \%$ to $0.0377 \%$ ).

\section{Conclusions and policy implications}

While we have been careful to outline underlying assumptions and possible uncertainties in our analysis, we have nevertheless estimated severity in a robust statistical framework, systematically accounting for possible biases. Identification of biases is possible only in an evidence synthesis framework, through the "triangulation" of multiple data sources: each source on its own provides a (potentially biased) view of only one aspect of the severity of an epidemic. The credible intervals reported fully reflect the uncertainty in the observed data, the estimation process, and some (though not all) model assumptions.

Finally, our study suggests a mild pandemic, characterised by case and infection severity ratios increasing between the two influenza waves, while the process of synthesis and reconciliation of the data available from different sources has highlighted the importance of transparent design of routine influenza surveillance to derive robust estimates of key measures of severity. Multiple information streams - and an established framework to interpret these data as quickly as possible-are critically important, particularly in light of the apparent resurgence ${ }^{10}$ of the pandemic $\mathrm{A} / \mathrm{H} 1 \mathrm{~N} 1$ strain in the $2010-11$ influenza season.

We thank all colleagues throughout the Health Protection Agency who contributed to data collection during the pandemic, Professor E Miller and her team for providing the sero-incidence data, and the medical staff of the chief medical officer who collected data on fatal cases.

Contributors: AMP performed the main statistical analysis, developed the model, and wrote the paper. RGP, BJP, and AC collated the data, contributed to model development, and helped revise the paper. BDMT and PJB contributed to statistical analysis, to model development, and to critical revisions of the paper. ML and DDA conceived and planned the project and contributed to model development and to critical revisions of the paper. RGP, ML, and DDA are the guarantors for the study. All authors gave final approval of the published paper and had full access to the data used in the study.

Funding: AMP, PJB, and DDA were funded by the UK Medical Research Council (grant MC_US_A030_0016.01). BDMT was also funded by the council (grant MC_US_A030_0022.01).DDA, RGP, BJP, and AC were funded by the UK Health Protection Agency. BJP was funded as a research fellow by the Hunter Medical Research Institute, Australia. ML was supported by the Models of Infectious Disease Agent Study Consortium from the National Institute of General Medical Sciences (award No U54GM088558). The content is the responsibility of the authors and does not necessarily represent the views of the National Institute of General Medical Sciences or the National Institutes of Health. The funders had no role in study design; the collection, analysis, and interpretation of data; in the writing of the report; or in the decision to publish the article.

Competing interests: All authors have completed the Unified Competing Interest form at www.icmje.org/coi_disclosure.pdf (available on request from the corresponding author) and declare: $\mathrm{ML}$ received consulting income in 2007-8 from the Avian/Pandemic Flu Registry, a project of Outcome Sciences (Cambridge, MA), which was sponsored by Roche, and has received consulting income or honorariums from Novartis and Pfizer. All other authors declare no support for the submitted work from anyone other than their employer; no financial relationships with any organisations that might have an interest in the submitted work in the previous three years; no other relationships or activities that could appear to have influenced the submitted work.
Ethical approval: None required.

Data sharing: No additional data available.

1 World Health Organization. Pandemic (H1N1) 2009-update 112. 2010. www.who.int/ csr/don/2010_08_06/en/index.html.

2 Lipsitch M, Riley S, Cauchemez S, Ghani A, Ferguson N. Managing and reducing uncertainty in an emerging influenza pandemic. N Engl J Med 2009;361:112-5.

3 Garske T, Legrand J, Donnelly C, Ward H, Cauchemez S, Fraser C, et al. Assessing the severity of the novel influenza A/H1N1 pandemic. BMJ 2009;339:b2840.

4 Nishiura H, Klinkenberg D, Roberts M, Heesterbeek J. Early epidemiological assessment of the virulence of emerging infectious diseases: a case study of an influenza pandemic. PloS One 2009;4:e6852.

5 Reed C, Angulo F, Swerdlow D, Lipsitch M, Meltzer M, Jernigan D, et al. Estimates of the prevalence of pandemic (H1N1) 2009, United States, April-July 2009. Emerging Infect Dis 2009:15:2004-7.

6 Wilson N, Baker MG. The emerging influenza pandemic: estimating the case fatality ratio. Euro Surveill 2009;14:pii=19255

7 Baker MG, Wilson N, Huang QS, Paine S, Lopez L, Bandaranayake D, et al. Pandemic influenza $A(\mathrm{H} 1 \mathrm{N1}) v$ in New Zealand: the experience from April to August 2009. Euro Surveill 2009;14:pii $=19319$.

8 Presanis AM, De Angelis D, Hagy A, Reed C, Riley S, Cooper B, et al. The severity of pandemic H1N1 influenza in the United States, from April to July 2009: a Bayesian analysis. PLOS Med 2009;6:e1000207.

9 Miller MA, Viboud C, Balinska M, Simonsen L. The signature features of influenza pandemics-implications for policy. N Engl J Med 2009;360:2695-8.

10 Health Protection Agency. Antiviral drugs for seasonal flu approved as HPA urges at-risk groups to get vaccinated. Health Protection Agency Press Release. 2010. www.hpa.org. uk/NewsCentre/NationalPressReleases/2010PressReleases/101213flu/.

11 Welliver R, Monto A, Carewicz O, Schatteman E, Hassman M, Hedrick J, et al. Effectiveness of oseltamivir in preventing influenza in household contacts: a randomized controlled trial. JAMA 2001;285:748-54.

12 Carrat F, Vergu E, Ferguson N, Lemaitre M, Cauchemez S, Leach S, et al. Time lines of infection and disease in human influenza: a review of volunteer challenge studies. $A m \mathrm{~J}$ Epidemiol 2008;167:775-85

13 Miller E, Hoschler K, Hardelid P, Stanford E, Andrews N, Zambon M. Incidence of 2009 pandemic influenza A H1N1 infection in England: a cross-sectional serological study. Lancet 2010;375:1100-8.

14 Donaldson L, Rutter P, Ellis B, Greaves F, Mytton O, Pebody R, et al. Mortality from pandemic A/H1N1 2009 influenza in England: public health surveillance study. BMJ 2009;339:b5213.

15 Pebody RG, McLean E, Zhao H, Cleary P, Bracebridge S, Foster K, et al. Pandemic influenza A (H1N1) 2009 and mortality in the United Kingdom: risk factors for death, Apri 2009 to March 2010. Euro Surveill 2010;15:pii.

16 Health Protection Agency, Health Protection Scotland, Communicable Disease Surveillance Centre, National Public Health Service for Wales. First few hundred (FF100) project: epidemiological protocols for comprehensive assessment of early swine influenza cases in the United Kingdom. 2009. www.hpa.org.uk/web/HPAwebFile/HPAweb_C/ 1257260453727

17 Health Protection Agency. Epidemiological report of pandemic (H1N1) 2009 in the UK. 2010. www.hpa.org.uk/Publications/InfectiousDiseases/Influenza/ 1010EpidemiologicalreportofpandemicH1N12009inUK/.

18 Presanis AM. The role of each item of evidence in estimating severity of novel pandemic (H1N1) 2009 influenza: a Bayesian synthesis. In preparation, 2011

19 Health Protection Agency. Method used to estimate new pandemic (H1N1) 2009 influenza cases in England. 2009. www.hpa.org.uk/web/HPAweb\&Page\&HPAwebAutoListName/ Page/1259151885940.

20 Evans BG, Charlett A, Powers C, Zhao H, Bermingham A, Smith G, et al. Has estimation of numbers of cases of pandemic influenza H1N1 in England in 2009 provided a useful measure of the occurrence of disease? In preparation,2011.

21 Hardelid P, Andrews NJ, Hoschler K, Stanford E, Baguelin M, Waight PA, et al. Assessment of baseline age-specific antibody prevalence and incidence of infection to novel influenza A/H1N1 2009. Health Technol Assess 2010;14:115-92.

22 Campbell CN, Mytton OT, McLean EM, Rutter PD, Pebody RG, Sachedina N, et al Hospitalization in two waves of pandemic influenza $\mathrm{A}(\mathrm{H} 1 \mathrm{~N} 1)$ in England. Epidemiol Infect 2010;26:1-10.

23 Grant A. Pandemic influenza deaths: capture-recapture estimate. Personal communication, 2010.

24 Lunn D, Spiegelhalter D, Thomas A, Best N. The BUGS project: evolution, critique and future directions (with discussion). Stat Med 2009;28:3049-82.

25 Inekweazu C. Clinical spectrum of disease caused by novel pandemic (H1N1) 2009 in a closed population setting: a sero-epidemiological study. International Conference on Emerging Infectious Diseases, Atlanta, 2010.

26 Influenzanet. FluSurvey. 2009. www.flusurvey.org.uk/.

27 FluWatch. Pandemic study. 2009. www.fluwatch.co.uk/.

28 Degail M. Concurrent invasive bacterial infections in confirmed pandemic (H1N1) 2009 influenza cases in England, 2009-2010. Health Protection Conference, 2010.

29 Dowell S, Whitney C, Wright C, Rose C, Schuchat A. Seasonal patterns of invasive pneumococcal disease. Emerging Infect Dis 2003;9:573-9.

30 Wallinga J, van Boven M, Lipsitch M. Optimizing infectious disease interventions during an emerging epidemic. Proc Natl Acad Sci USA 2010;107:923-8.

31 Birrell PJ, Ketsetzis G, Gay NJ, Cooper BS, Presanis AM, Harris RJ, et al. Bayesian modelling to unmask and predict the influenza A/H1N1pdm dynamics in London. Submitted,2011.

32 Bird SM. Like-with-like comparisons? Comment on Miller et al. Lancet 2010;376:684.

33 Cowling BJ, Chan KH, Fang VJ, Lau LLH, So HC, Fung ROP, et al. Comparative epidemiology of pandemic and seasonal influenza $\mathrm{A}$ in households. N Engl J Med 2010;362:2175-84.

34 Bandaranayake D, Bissielo A, Huang S, Wood T. Seroprevalence of the 2009 influenza A (H1N1) pandemic in New Zealand. 2010. www.moh.govt.nz/moh.nst/pagesmh/10124 \$File/seroprevalence-flu-2009.pdf.

35 Harris R, Kafatos G. Statistical analysis preliminary report: FF100 serology. Health Protection Agency internal report, 2010. 


\section{What is already known on this topic}

Initial estimates of the severity of the $2009 \mathrm{~A} / \mathrm{H} 1 \mathrm{~N} 1$ influenza pandemic were highly uncertain, with later estimates suggesting a relatively mild pandemic but with an age distribution of infections different from that for seasonal influenza

Previous studies of the severity of the 2009 A/H1N1 influenza pandemic in England have not fully accounted for biases, have not made comprehensive use of all available relevant evidence to quantify the uncertainty in these severity measures, and have not provided an assessment of changes in severity nor of the adequacy of routine surveillance systems

\section{What this paper adds}

This study is the first to provide a complete overview of the severity of the first two waves of the 2009 pandemic A/H1N1 influenza outbreak in England, synthesising all available relevant influenza surveillance data

The analysis fully accounts for biases and under-ascertainment of confirmed cases in each surveillance system and accounts robustly for uncertainty in the data

36 Hadler JL, Konty K, McVeigh KH, Fine A, Eisenhower D, Kerker B, et al. Case fatality rates based on population estimates of influenza-like illness due to novel $\mathrm{H} 1 \mathrm{~N} 1$ influenza: New York City, May-June 2009. PloS One 2010;5:e11677.

37 Wu JT, Ma ESK, Lee CK, Chu DKW, Ho PL, Shen AL, et al. The infection attack rate and severity of 2009 pandemic H1N1 influenza in Hong Kong. Clin Infect Dis 2010;51:1184-91.

Accepted: 27 June 2011

\section{Cite this as: BMJ 2011;343:d5408}

This is an open-access article distributed under the terms of the Creative Commons Attribution Non-commercial License, which permits use, distribution, and reproduction in any medium, provided the original work is properly cited, the use is non commercial and is otherwise in compliance with the license. See: http://creativecommons.org/licenses/bync/2.0/ and http://creativecommons.org/licenses/by-nc/2.0/legalcode. 


\section{Tables}

\section{Table $1 \mid$ Measures of severity of influenza infection}

\begin{tabular}{lll} 
Quantity & \multicolumn{1}{c}{ Definition } & Estimated by \\
Case fatality ratio & Probability that an infection leads to death & Noaths/No of infections \\
\hline Case intensive care admission ratio & Probability that an infection leads to intensive care admission & No of intensive care admissions/No of infections \\
\hline Case hospitalisation ratio & Probability that an infection leads to hospital admission & No of hospital admissions/No of infections \\
\hline Symptomatic case fatality ratio & Probability that a symptomatic infection leads to death & No of deaths/No of symptomatic infections \\
\hline $\begin{array}{l}\text { Symptomatic case intensive care admission } \\
\text { ratio }\end{array}$ & $\begin{array}{l}\text { Probability that a symptomatic infection leads to intensive care } \\
\text { admission }\end{array}$ & $\begin{array}{l}\text { No of intensive care admissions/No of symptomatic } \\
\text { infections }\end{array}$ \\
\hline Symptomatic case hospitalisation ratio & $\begin{array}{l}\text { Probability that a symptomatic infection leads to hospital } \\
\text { admission }\end{array}$ & No of hospital admissions/No of symptomatic infections \\
\hline Infection attack rate & Proportion of the population cumulatively infected & No of infections/No of population \\
\hline Symptomatic infection attack rate & $\begin{array}{l}\text { Proportion of the population cumulatively infected with febrile No of symptomatic infections/No of population } \\
\text { influenza-like illness }\end{array}$ &
\end{tabular}


Table 2| Details of model of severity of 2009 pandemic A/H1N1 influenza in England: model parameters; their prior distributions or functional forms; and evidence (direct or indirect) contributing to the parameter estimates

$\begin{array}{llll}\begin{array}{l}\text { Parameter } \\ \text { (description) }\end{array} & \begin{array}{c}\text { Prior distribution or } \\ \text { functional form }\end{array} & \text { Rationale } & \text { Direct } \\ \text { Conditional probabilities } & & & \text { Indirect }\end{array}$

Conditional probabilities

$\mathrm{C}_{\mathrm{a}, \mathrm{t}, \mathrm{Inf} \text { Pop }}$ (infection attack Dirichlet $(1,1,1)$ $\begin{array}{lll}\text { Vague prior assuming we know nothing } & \text { Serological data for summer wave } & \text { Assumption (see } d_{a, t, s} \\ \text { a priori (that is, a flat prior covering the } & \text { (binomial likelihoods for observed baseline below) of a similar bias }\end{array}$ $\begin{array}{lll}\text { Vague prior assuming we know nothing Serological data for summer wave } & \text { Assumption (see } d_{a, t, s} \\ \text { a priori (that is, a flat prior covering the } & \text { (binomial likelihoods for observed baseline below) of a similar bias }\end{array}$ rate) 0 to 1 range). Age specific and pandemic number of positive samples, the HPA case estimates in with the corresponding serial prevalences the two waves. The as the proportion and total numbers of remaining data and mode samples as the size)

\begin{tabular}{|c|c|c|c|c|}
\hline $\begin{array}{l}\mathrm{C}_{\mathrm{S|lnf}} \text { (proportion } \\
\text { symptomatic) }\end{array}$ & Beta $(40,60)$ & $\begin{array}{l}\text { Informative prior: mean } 40 \% \text { ( } 95 \% \text { prior } \\
\text { probability of lying in } 30 \% \text { to } 50 \%) .^{25} \\
\text { Assumed equal across age groups and } \\
\text { waves }\end{array}$ & None & $\begin{array}{l}\text { All the data and model } \\
\text { assumptions }\end{array}$ \\
\hline $\begin{array}{l}\mathrm{C}_{\mathrm{a}, \mathrm{t}, \mathrm{H} S \mathrm{~S}} \text { (symptomatic case } \\
\text { hospitalisation ratio) }\end{array}$ & Uniform $\left(0, \mathrm{c}_{\mathrm{a}, \mathrm{H} \mid \mathrm{C}}\right)$ & $\begin{array}{l}\text { Informative prior constraining the } \\
\text { symptomatic case hospitalisation ratio } \\
\text { to lie between } 0 \text { and the confirmed } \\
\text { case hospitalisation ratio. Age and }\end{array}$ & None & $\begin{array}{l}\text { The observed number of } \\
\text { hospitalisations. The } \\
\text { remaining data and model } \\
\text { assumptions }\end{array}$ \\
\hline
\end{tabular}
wave specific

$\mathrm{C}_{\mathrm{a}, \mathrm{H} \mid \mathrm{C}}$ (confirmed case Beta distributions, one for Informative priors, reflecting estimates None hospitalisation ratio) each age group of the confirmed case hospitalisation All the data and model ratio obtained from a parametric mixture survival model ${ }^{18}$ fitted to data on laboratory confirmed cases. Averaged across all age groups, this estimate is $1.2 \%(0.97 \%$ to $1.49 \%)$. Age specific

$\mathrm{C}_{\mathrm{at \perp H}}$ (probability of $\quad \operatorname{Beta}(1,1)$ intensive care admission given hospitalisation)

\section{$\mathrm{C}_{\mathrm{a}, \mathrm{D}, \mathrm{D} \mid \mathrm{H}}$ (probability of $\quad \operatorname{Beta}(1,1)$} death given

hospitalisation)

\section{Vague prior assuming we know nothing} a priori (that is, prior mean $50 \%$ with $95 \%$ of prior mass lying in $2.5 \%$ to $97.5 \%)$. Age and wave specific
Observed ratio of intensive care admissions to hospitalisations among confirmed cases with non-missing data (binomial likelihood for the number of intensive care admissions, with $\mathrm{c}_{\mathrm{at}, \mathrm{ll}}$ as the proportion and the number of hospitalisations as the size)

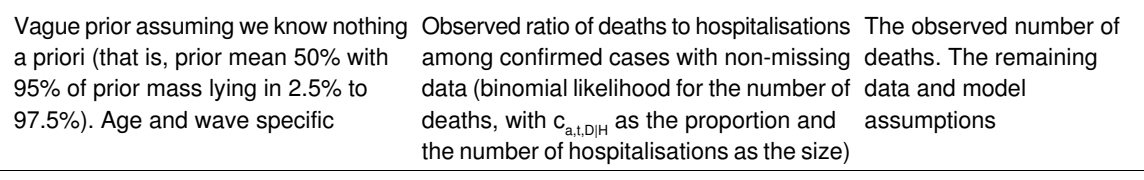

The remaining data and model assumptions

Detection probabilities

$\mathrm{d}_{\mathrm{ats} \text { ( }}$ (proportion of $\quad$ Beta $(1,1) \quad$ Vague prior assuming we know nothing None

number symptomatic

"observed" in the HPA

case estimates)

a priori (that is, prior mean $50 \%$ with

$95 \%$ of prior mass lying in $2.5 \%$ to

$97.5 \%)$. This prior is assumed only for the summer wave. The odds ratio of

this proportion in the autumn-winter

wave relative to the summer wave is assumed to lie between 0.7 and 1.3. Age specific.

$\mathrm{d}_{\mathrm{tH}}$ (proportion of $\quad \operatorname{Beta}(1,1)$

number of

hospitalisations that are

observed)
Vague prior assuming we know nothing None

a priori (that is, prior mean $50 \%$ with

$95 \%$ of prior mass lying in $2.5 \%$ to

$97.5 \%$ ). Wave specific, but assumed equal across age groups.

Informative prior reflecting an estimate None

of this proportion taken from a

capture-recapture study ${ }^{23}$ : (mean 90\%

with $95 \%$ of prior probability lying in

$80 \%$ to $97 \%$ ). Wave specific, but

assumed equal across age groups.
The HPA case estimates and the serological data. The remaining data and model assumptions $d_{t, D}$ (proportion of the $\operatorname{Beta}(45,5)$ are observed)

\section{Product of component conditional None} probabilities

Cardin (case fatality ratio)

Product of component conditional

None

$\mathrm{c}_{\mathrm{a}, \mathrm{D}, \mathrm{S}}$ (symptomatic case $\mathrm{c}_{\mathrm{a}, \mathrm{t}, \mathrm{D} \mid \mathrm{S}}=\mathrm{C}_{\mathrm{a}, \mathrm{t}, \mathrm{D} \mid \mathrm{H}} \times \mathrm{C}_{\mathrm{a}, \mathrm{t}, \mathrm{H} \mid \mathrm{S}}$

probabilities

fatality ratio)

All the data and model assumptions

The observed number of

hospitalisations. The remaining data and model assumptions

The observed number of deaths. The remaining data and model assumptions

All the data and model assumptions 
Table 2 (continued)

\begin{tabular}{|c|c|c|c|c|}
\hline \multirow{2}{*}{$\begin{array}{l}\text { Parameter } \\
\text { (description) }\end{array}$} & \multirow{2}{*}{$\begin{array}{l}\text { Prior distribution or } \\
\text { functional form }\end{array}$} & \multicolumn{3}{|c|}{ Evidence } \\
\hline & & \multicolumn{2}{|l|}{ Rationale } & Indirect \\
\hline $\begin{array}{l}c_{a, t, \| n f} \text { (case intensive } \\
\text { care ratio) }\end{array}$ & $\mathrm{C}_{\mathrm{a}, \mathrm{t}, \| \mathrm{nf}}=\mathrm{C}_{\mathrm{a}, \mathrm{t}, \mathrm{\|}, \mathrm{H}} \times \mathrm{C}_{\mathrm{a}, \mathrm{t}, \mathrm{H}, \mathrm{|}} \times \mathrm{C}_{\mathrm{a}, \mathrm{t}, \mathrm{S} \mid \mathrm{nf}}$ & $\begin{array}{l}\text { Product of component conditional } \\
\text { probabilities }\end{array}$ & None & $\begin{array}{l}\text { All the data and model } \\
\text { assumptions }\end{array}$ \\
\hline $\begin{array}{l}\mathrm{c}_{\mathrm{a}, \mathrm{t}, \mid \mathrm{S}} \text { (symptomatic case } \\
\text { intensive care ratio) }\end{array}$ & $\mathrm{C}_{\mathrm{a}, \mathrm{t}, \mathrm{t}, \mathrm{S}}=\mathrm{C}_{\mathrm{a}, \mathrm{t}, \mathrm{\|}, \mathrm{H}} \times \mathrm{C}_{\mathrm{a}, \mathrm{t}, \mathrm{H} \mid \mathrm{S}}$ & $\begin{array}{l}\text { Product of component conditional } \\
\text { probabilities }\end{array}$ & None & $\begin{array}{l}\text { All the data and model } \\
\text { assumptions }\end{array}$ \\
\hline \multicolumn{5}{|c|}{ Number of individuals at each severity level } \\
\hline $\begin{array}{l}\mathrm{N}_{a, \text { Pop }} \text { (population size of } \\
\text { England in age group a) }\end{array}$ & $\mathrm{N} / \mathrm{A}$ & $\begin{array}{l}\text { Assumed constant, taken from ONS } \\
2008 \text { population estimates }\end{array}$ & ONS 2008 population estimates & None \\
\hline $\begin{array}{l}\mathrm{N}_{\mathrm{a}, \mathrm{t}, \text { Inf }} \text { (number of } \\
\text { infections) }\end{array}$ & $\mathrm{N}_{\mathrm{a}, \mathrm{t}, \operatorname{lnf}}=\mathrm{C}_{\mathrm{a}, \mathrm{t}, \mathrm{Inf} \mid \mathrm{Pop}} \times \mathrm{N}_{\mathrm{a}, \mathrm{Pop}}$ & $\begin{array}{l}\text { Product of infection attack rate and } \\
\text { population size }\end{array}$ & None & $\begin{array}{l}\text { All the data and model } \\
\text { assumptions }\end{array}$ \\
\hline $\begin{array}{l}\mathrm{N}_{\mathrm{a}, \mathrm{t}, \mathrm{S}} \text { (number of } \\
\text { symptomatic infections) }\end{array}$ & $\mathrm{N}_{\mathrm{a}, \mathrm{t}, \mathrm{S}}=\mathrm{C}_{\mathrm{S} \mid \operatorname{lnf}} \times \mathrm{N}_{\mathrm{a}, \mathrm{t}, \ln f}$ & $\begin{array}{l}\text { Product of proportion symptomatic and } \\
\text { number of infections }\end{array}$ & None & $\begin{array}{l}\text { All the data and model } \\
\text { assumptions }\end{array}$ \\
\hline $\begin{array}{l}\mathrm{N}_{\mathrm{a}, \mathrm{t}, \mathrm{SB}} \text { (number of } \\
\text { symptomatic infections } \\
\text { as estimated by HPA, } \\
\text { assumed biased } \\
\text { downwards) }\end{array}$ & $\mathrm{N}_{\mathrm{a}, \mathrm{t}, \mathrm{SB}}=\mathrm{d}_{\mathrm{a}, \mathrm{t}, \mathrm{S}} \times \mathrm{N}_{\mathrm{a}, \mathrm{t}, \mathrm{S}}$ & $\begin{array}{l}\text { Product of bias in HPA case estimates } \\
\text { and number of symptomatic infections }\end{array}$ & $\begin{array}{l}\text { HPA case estimates (normal likelihood for } \\
\text { the middle estimate, with lower and upper } \\
\text { estimates assumed to be } 3 \text { standard } \\
\text { deviations away from the mid-estimate). }\end{array}$ & $\begin{array}{l}\text { The remaining data and } \\
\text { model assumptions }\end{array}$ \\
\hline $\begin{array}{l}\mathrm{N}_{\mathrm{a}, \mathrm{t}, \mathrm{H}} \text { (number of } \\
\text { hospitalisations) }\end{array}$ & $\mathrm{N}_{\mathrm{a}, \mathrm{t}, \mathrm{H}}=\mathrm{C}_{\mathrm{a}, \mathrm{t}, \mathrm{H} \mid \mathrm{S}} \times \mathrm{N}_{\mathrm{a}, \mathrm{t}, \mathrm{S}}$ & $\begin{array}{l}\text { Product of symptomatic case } \\
\text { hospitalisation ratio and number of } \\
\text { symptomatic infections }\end{array}$ & $\begin{array}{l}\text { Observed number of hospitalisations } \\
\text { (binomial likelihood for the observed } \\
\text { hospitalisations with the detection } \\
\text { probability } \mathrm{d}_{\mathrm{t}, \mathrm{H}} \text { as the proportion and the } \\
\text { "true" number of hospitalisations } \mathrm{N}_{\mathrm{a}, \mathrm{t}, \mathrm{H}} \text { as } \\
\text { the size) }\end{array}$ & $\begin{array}{l}\text { The remaining data and } \\
\text { model assumptions }\end{array}$ \\
\hline $\begin{array}{l}\mathrm{N}_{\mathrm{a}, \mathrm{t}, \mathrm{I}} \text { (number of } \\
\text { intensive care } \\
\text { admissions) }\end{array}$ & $\mathrm{N}_{\mathrm{a}, \mathrm{t}, \mathrm{I}}=\mathrm{C}_{\mathrm{a}, \mathrm{t}, \mathrm{\|}, \mathrm{H}} \times \mathrm{N}_{\mathrm{a}, \mathrm{t}, \mathrm{H}}$ & $\begin{array}{l}\text { Product of intensive care admission to } \\
\text { hospitalisation ratio and number of } \\
\text { hospitalisations }\end{array}$ & None & $\begin{array}{l}\text { All the data and model } \\
\text { assumptions }\end{array}$ \\
\hline $\mathrm{N}_{\mathrm{a}, \mathrm{t}, \mathrm{D}}$ (number of deaths) & $\mathrm{N}_{\mathrm{a}, \mathrm{t}, \mathrm{D}}=\mathrm{C}_{\mathrm{a}, \mathrm{t}, \mathrm{D} \mid \mathrm{H}} \times \mathrm{N}_{\mathrm{a}, \mathrm{t}, \mathrm{H}}$ & $\begin{array}{l}\text { Product of death to hospitalisation ratio } \\
\text { and number of hospitalisations }\end{array}$ & $\begin{array}{l}\text { Observed number of deaths (binomial } \\
\text { likelihood with the detection probability } d_{t, D} \\
\text { as the proportion and the "true" number of } \\
\text { deaths } N_{a, t, D} \text { as the size) }\end{array}$ & $\begin{array}{l}\text { The remaining data and } \\
\text { model assumptions }\end{array}$ \\
\hline
\end{tabular}


Table 3| Posterior summaries of severity of 2009 pandemic A/H1N1 influenza in England. Values are posterior median estimates (95\% credible intervals) for all ages

\begin{tabular}{|c|c|c|}
\hline \multirow[b]{2}{*}{ Parameter } & \multicolumn{2}{|c|}{ Wave of influenza } \\
\hline & June-August & September-February \\
\hline \multicolumn{3}{|l|}{ Symptomatic case severity ratio (\%): } \\
\hline Hospitalisation (sCHR) & 0.54 (0.33 to 0.82$)$ & 0.55 (0.28 to 0.89$)$ \\
\hline Intensive care admission (sCIR) & 0.05 (0.03 to 0.08$)$ & $0.10(0.05$ to 0.16$)$ \\
\hline Fatality (sCFR) & 0.015 (0.010 to 0.022$)$ & 0.025 (0.013 to 0.040$)$ \\
\hline \multicolumn{3}{|l|}{ Infection severity ratio (\%): } \\
\hline Hospitalisation (CHR) & $0.19(0.12$ to 0.29$)$ & 0.19 (0.10 to 0.32$)$ \\
\hline Intensive care admission (CIR) & $0.02(0.01$ to 0.03$)$ & $0.03(0.02$ to 0.06$)$ \\
\hline Fatality (CFR) & 0.005 (0.004 to 0.008$)$ & $0.009(0.004$ to 0.014$)$ \\
\hline \multicolumn{3}{|l|}{ Numbers infected, by severity*: } \\
\hline Total $\left(\mathrm{N}_{\operatorname{lnf}}\right)$ & 1750000 (1 235000 to 2470000$)$ & 3909000 (2316 000 to 8223000$)$ \\
\hline Symptomatic $\left(\mathrm{N}_{\mathrm{S}}\right)$ & 606100 (419 300 to 886300$)$ & 1352000 (829 900 to 2806000$)$ \\
\hline Hospitalisation $\left(\mathrm{N}_{\mathrm{H}}\right)$ & 3200 (2 300 to 4700$)$ & 7500 (5900 to 9700$)$ \\
\hline Intensive care admission $\left(\mathrm{N}_{1}\right)$ & $310(200$ to 480$)$ & $1340(1030$ to 1790$)$ \\
\hline Fatality $\left(\mathrm{N}_{\mathrm{D}}\right)$ & $90(80$ to 110$)$ & $340(310$ to 380$)$ \\
\hline \multicolumn{3}{|l|}{ Attack rates (\%): } \\
\hline Infection (IAR) & $3.4(2.4$ to 4.8$)$ & $7.7(4.6$ to 15.0$)$ \\
\hline Symptomatic (SAR) & $1.2(0.8$ to 1.7$)$ & 2.7 (1.7 to 5.3$)$ \\
\hline Proportion of infections that are symptomatic $\left(\mathrm{c}_{\mathrm{s} \operatorname{lnf}}\right)(\%)$ & 35 (26 to 45$)$ & 35 (26 to 45$)$ \\
\hline \multicolumn{3}{|l|}{ Detection probability $(\%)$ : } \\
\hline Symptomatic $\left(d_{\mathrm{s}}\right)$ & 40 (24 to 59$)$ & $36(19$ to 57$)$ \\
\hline Hospitalisation $\left(\mathrm{d}_{\mathrm{H}}\right)$ & 30 (20 to 43$)$ & $20(15$ to 25$)$ \\
\hline Fatality $\left(d_{D}\right)$ & 88 (78 to 95$)$ & 90 (80 to 96$)$ \\
\hline
\end{tabular}

*Numbers rounded to the nearest 100 for infections, symptomatic infections, and hospitalisations, and to the nearest 10 for intensive care admissions and deaths. See table 2 for list of abbreviations and meanings. 
Table 4| Posterior summaries of infection attack rates in 2009 pandemic A/H1N1 influenza in England, by age and wave of influenza. Values are posterior median estimates $(95 \%$ credible intervals)

Infection attack rate (\%)

Age (years) June-August wave September-February wave

Total

$<1 \quad 8.0$ (3.3 to 15.7$) \quad 6.1$ (2.4 to 18.4$) \quad 14.5$ (6.6 to 31.5$)$

\begin{tabular}{llll}
$1-4$ & $7.2(3.3$ to 13.3$)$ & $15.0(5.3$ to 53.1$)$ & 22.7 (9.9 to 62.3$)$ \\
\hline
\end{tabular}

5-14 $\quad 10.0(5.9$ to 14.9$) \quad 19.3(9.1$ to 52.4$) \quad 29.5(16.9$ to 64.1$)$

15-24 3.7 (1.8 to 7.3$) \quad 7.0$ (3.4 to 22.3) 10.9 (6.3 to 27.1$)$

25-44 $2.8(1.1$ to 6.9$) \quad 5.2(2.1$ to 19.4$) \quad 8.2$ (3.7 to 24.7$)$

45-64 $\quad 1.4(0.5$ to 3.4$) \quad 5.0(1.5$ to 20.5$) \quad 6.4(2.3$ to 22.9$)$

$\begin{array}{llll}\geq 65 & 0.3(0.1 \text { to } 1.4) & 0.5(0.1 \text { to } 3.7) & 0.8(0.2 \text { to } 4.9)\end{array}$

Total $\quad 3.4(2.4$ to 4.8$) \quad 7.7(4.6$ to 15.0$) \quad 11.2(7.4$ to 18.9$)$




\section{Figures}

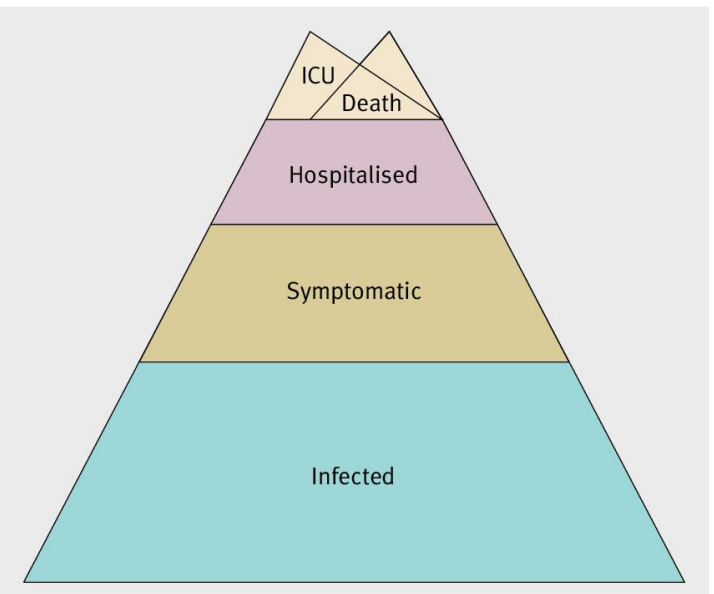

Fig 1 Severity levels for infection with pandemic A/H1N1 influenza. Each level is assumed to be a subset of the level below, with admission to intensive care (ICU) and death assumed to be overlapping subsets of hospitalisation. We therefore assume that no pandemic $\mathrm{A} / \mathrm{H} 1 \mathrm{~N} 1$ deaths occurred outside hospital

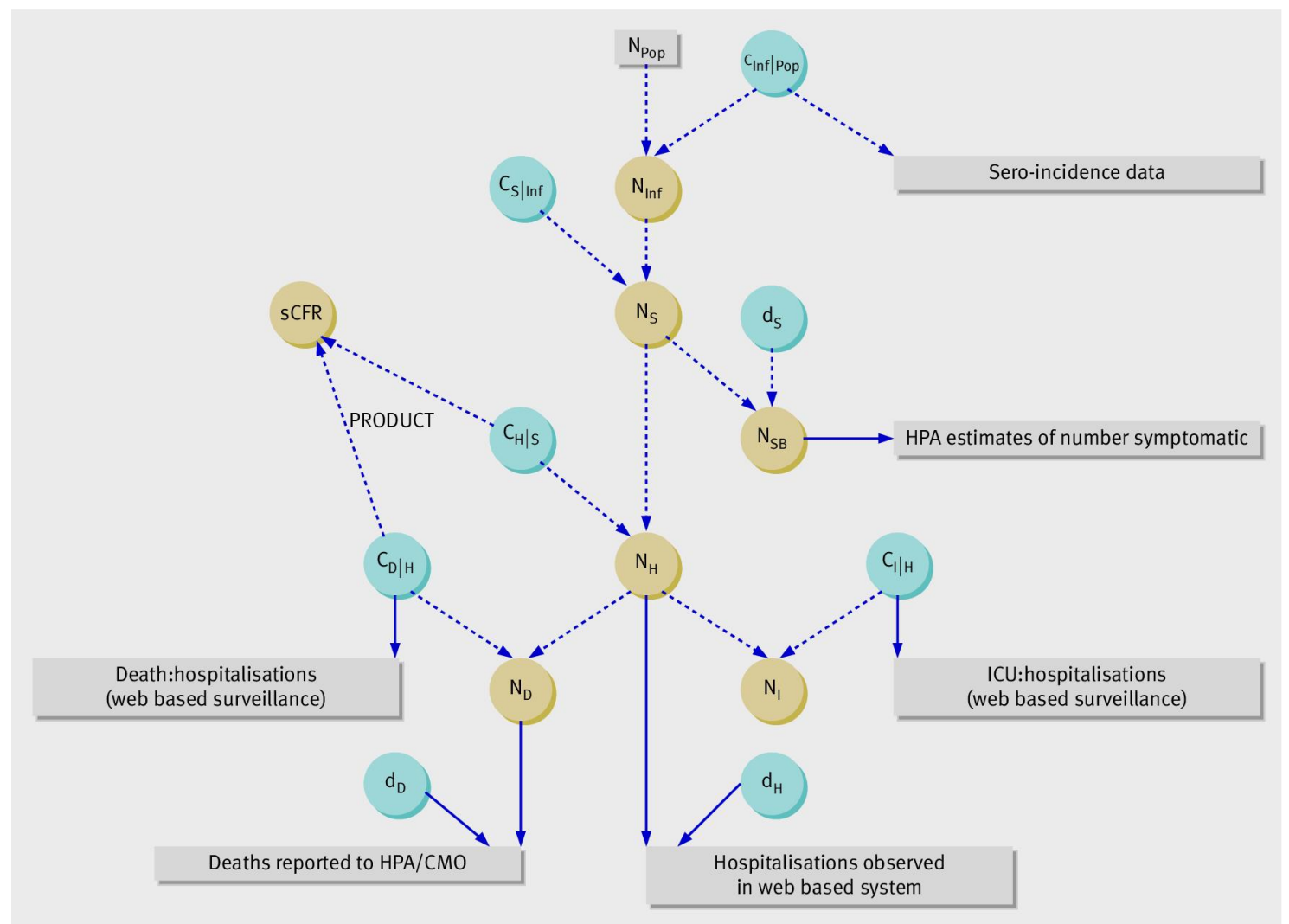

Fig 2 Schematic illustration of relation between data (rectangles) and the quantities of interest (parameters, in circles) in model of severity of 2009 pandemic A/H1N1 influenza in England (see table 2 for descriptions of the parameters). The data and parameters shown are for one age group in the summer wave of influenza, and the age and time period indices are not shown for conciseness. $\mathrm{N}_{\text {pop }}$ (population size of England in age group) is an (observed) constant, blue circles represent parameters on which we placed prior distributions (reflecting our knowledge about these before the analysis) whether informative or not. Solid lines represent direct evidence, and broken lines represent functional relationships: information flows from the data directly through the solid lines to the parameters, then indirectly through the broken lines to other parameters. Only the symptomatic case fatality ratio (SCFR) is shown, with the other infection and case severity ratios left out for conciseness. (See table $2 \Downarrow$ for full list of abbreviations) 

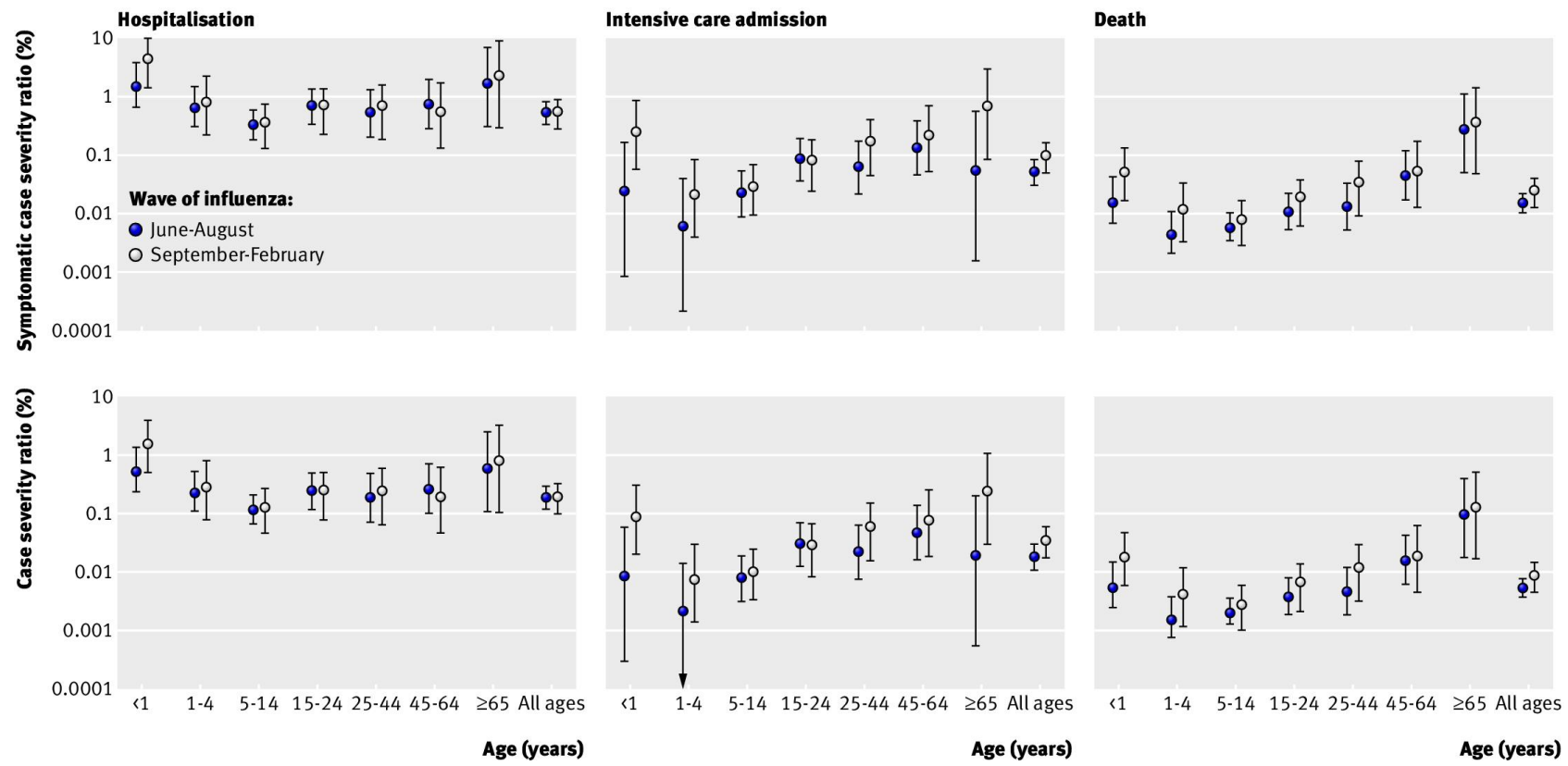

Fig 3 Posterior distribution of symptomatic case severity ratios (top panels) and case severity ratios (bottom panels) in 2009 pandemic A/H1N1 influenza in England, by wave of influenza and age group. Values are medians (95\% credible intervals) on a log scale
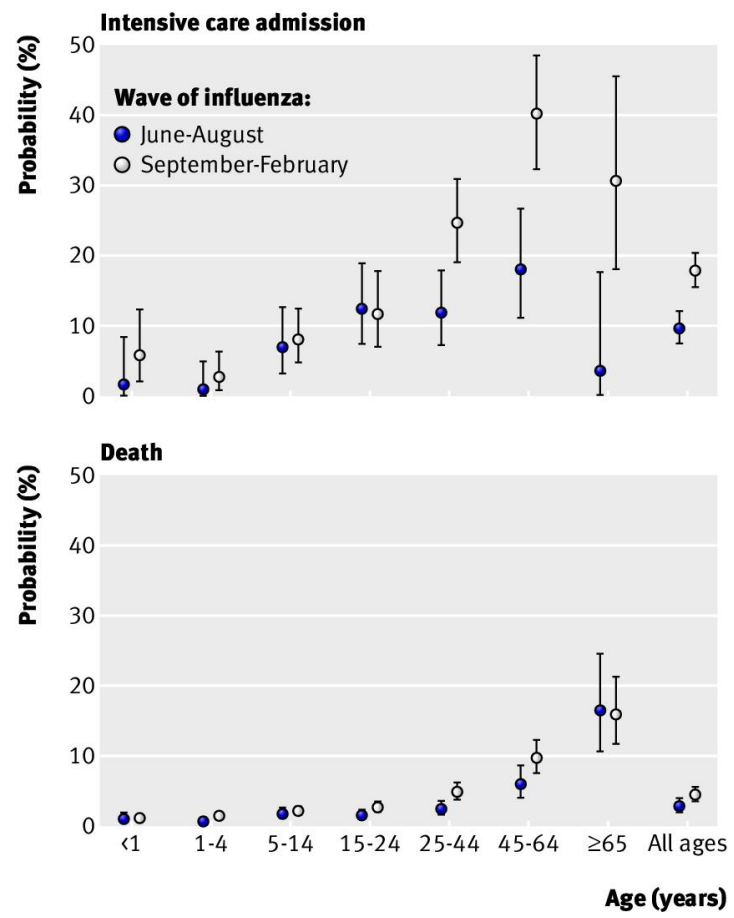

Fig 4 Posterior distribution of probabilities of admission to intensive care (top panel) and death (bottom panel) among hospitalised cases in 2009 pandemic A/H1N1 influenza in England, by wave of influenza and age group. Values are medians (95\% credible intervals) 